\title{
Prosthetic Rehabilitation of Atrophic Maxillary Anterior Region Using Autogenous Block Graft with Dental Implants
}

\author{
Vandita Srivastva, Neeteesh K Shukla ${ }^{*}$, Nimmi Gupta, Aswin Kumar \\ Student, MDS Work attributed in division of Prosthodontics, FODS, IMS, BHU, Varanasi-221005
}

DOI: $10.36348 /$ sjodr.2020.v05i03.013

| Received: 19.03.2020 | Accepted: 27.03.2020 | Published: 30.03.2020

*Corresponding author: Neeteesh K Shukla

\section{Abstract}

Dental implants are popular treatment option for replacement of missing teeth. Teeth loss causes alveolar bone resorption. Implant placement may require sufficient bone volume. Therefore bone augmentation can be done prior to implant placement. For bone augmentation autograft, allografts, xenografts and synthetic materials can be used. After augmentation implants can be placed successfully. In this case report autogenous block graft is taken for augmentation. Rehabilitation of edentulous region is done by implant placement.

Keywords: Prosthetic Rehabilitation Atrophic Maxillary Dental Implants.

Copyright @ 2020: This is an open-access article distributed under the terms of the Creative Commons Attribution license which permits unrestricted use, distribution, and reproduction in any medium for non-commercial use (NonCommercial, or CC-BY-NC) provided the original author and source are credited.

\section{INTRODUCTION}

Missing teeth replacement with dental implants is predictable and successful treatment option. Implant placement requires sufficient amount of bone. Most common causes of missing teeth are trauma, periapical infection and periodontal diseases [1]. After extraction of teeth resorption of alveolar bone takes place. Replacement of maxillary anterior teeth is very challenging due to aesthetic reasons [2]. Due to resorption implants cannot be placed in prosthetically driven manner. Therefore bone augmentation in maxillary anterior should be done prior to implant placement. Bone augmentation can be done with autograft, allograft, xenografts and synthetic materials [3]. Autogenous bone contains osteogenic, osteoconductive and osteoinductive properties. Autogenous bone augmentation carries no risk of immunogenic reactions. Therefore autogenous bone grafts have been considered as gold standard in bone augmentation procedures. Certain limitations of autografts include donor site morbidity, second surgical site, unpredictable resorption and limited bone volume of graft $[4,5]$.

Autogenous grafts can be taken extraorally and intraorally. Extraoral sites include calvarium, tibia and iliac crest. Dental implants do not need large amount of bone and extraoral grafts need hospitalisation and morbidity. Therefore intraoral sites are preferred for autogenous graft. Grafts can be taken from mandibular symphysis and ramus $[6,7]$.

\section{CASE REPORT}

A 22 years old male patient reported to department of Prosthodontics, Banaras Hindu University with chief complaint of missing right maxillary central incisor and left central and lateral incisor from three years due to trauma (figure 1a). Patient has told all possible treatment options. Patient decided to go for dental implant supported fixed prosthesis. He had a non-contributory medical history. All the necessary investigation was done. Denta scan was done. Bone width in maxillary anterior region was $2.4 \mathrm{~mm}$ on denta scan (figure $1 \mathrm{~b}$ ), which is insufficient for implant placement. So, autogenous block graft was planned for augmentation. Figure $1 \mathrm{a}$ and $1 \mathrm{~b}$ preoperative intraoral and dentascan photographs

\section{Surgical procedure}

Under local anesthesia, an intrasulcular incision with two vertical releasing incisions was given in maxillary anterior region and a full thickness mucoperiosteal flap was reflected (figure 2a). In anterior mandible, incision was given, sympysis was exposed. With the help of straight fissure bur, two rectangles were marked on both sides of symphysis (figure 2b). Superior border of rectangle should be 5 $\mathrm{mm}$ below the root apex. Inferior border should be 5 $\mathrm{mm}$ above the lower border of mandible. These borders were confirmed by radiographs by placing gutta purcha. Laterally the borders of rectangle should be $5 \mathrm{~mm}$ anterior to mental foramen. Then ostetomes were used 
to free the grafts (figure $2 \mathrm{c}, 2 \mathrm{~d}$ ). Then suture was placed in mandibular anterior region. Decortications were performed in anterior maxillary region. Sharp borders of graft was trimmed and adapted to recipient site. When grafts adapted properly, those were tightened with screw (figure 3a). Space was filled with sticky bone (iprf+bone graft) (figure 3b, 3c). Collagen membrane was placed (figure $3 \mathrm{~d}$ ). Suture was placed in maxillary anterior region (figure 4a). Post operative instructions were given to the patient. After 4 weeks of grafting, removable provisional restorations were given (figure $4 b$ ). After six months of healing, denta scan was done. In dentascan, bone width was $6.1 \mathrm{~mm}$ (figure 5a). After six months, surgical re-entry was performed and screw was removed (figure 5b). Two implants of size $4.2 \times 13 \mathrm{~mm}$ were placed (figure $5 \mathrm{c}$ ). Healing cap was placed (figure 5d) and Suture was given.

Figure 2- full thickness mucoperiosteal flap reflection (figure 2a), two rectangles marked on both sides of symphysis (figure 2b), and free autogenous bone grafts (figure $2 \mathrm{c}, 2 \mathrm{~d}$ ).

Figure 3- grafts adapted properly, and tightened with screw (figure 3a), Space was filled with sticky bone (figure $3 \mathrm{~b}, 3 \mathrm{c}$ ), and Collagen membrane placed (figure 3d).

Figure 4- Suture placed in maxillary anterior region (figure $4 a$ ), after 4 weeks of grafting, removable provisional restoration given (figure $4 b$ ).

Figure 5- denta scan, bone width taken (figure 5a), after six months, surgical re-entry was performed and screw was removed (figure 5b), Two implants of size $4.2 \times 13 \mathrm{~mm}$ were placed (figure $5 \mathrm{c}$ ), and Healing cap was placed (figure $5 \mathrm{~d}$ ).

\section{Prosthetic phase}

After 3 months of implant placement, impression coping was attached and implant impression was taken with addition silicone (figure 6a). Model was poured and abutments were prepared (figure 6b). Shade matching was done. All ceramic prosthesis was fabricated and tried in patient's mouth (figure 6c). Occlusal corrections were done and final prosthesis was cemented (figure 7a, 7b, 7c).

Figure 6- impression coping was attached and implant impression was taken with addition silicone (figure 6a), Model was poured and abutments were prepared (figure 6b), and all ceramic prosthesis was fabricated and tried in patients mouth (figure 6c).

Figure 7a, 7b, 7c- Occlusal corrections were done and final prosthesis was cemented.

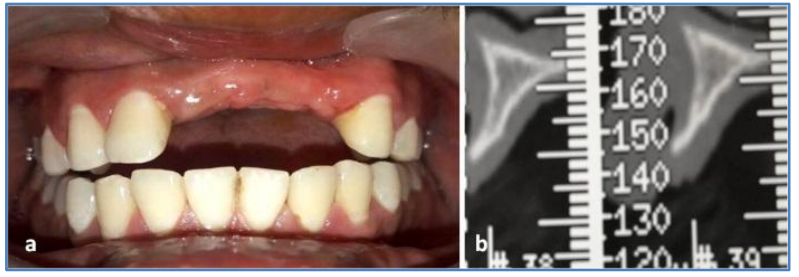

Fig-1

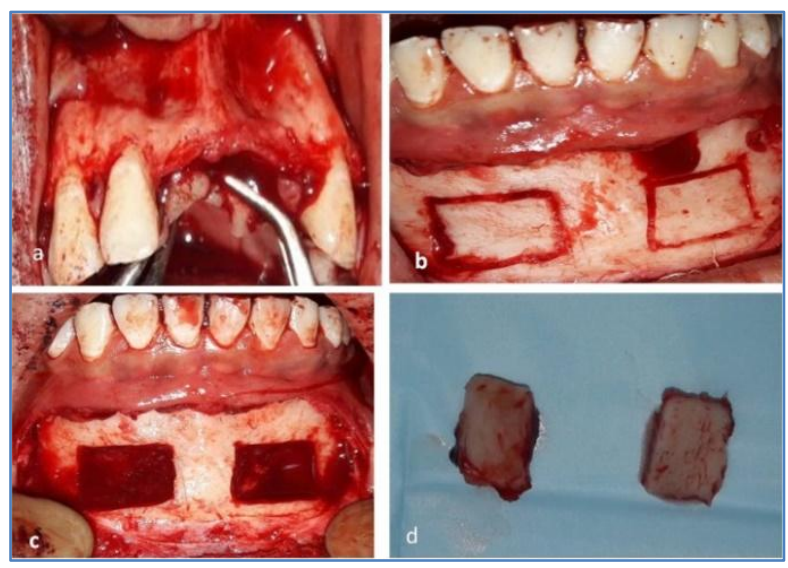

Fig-2

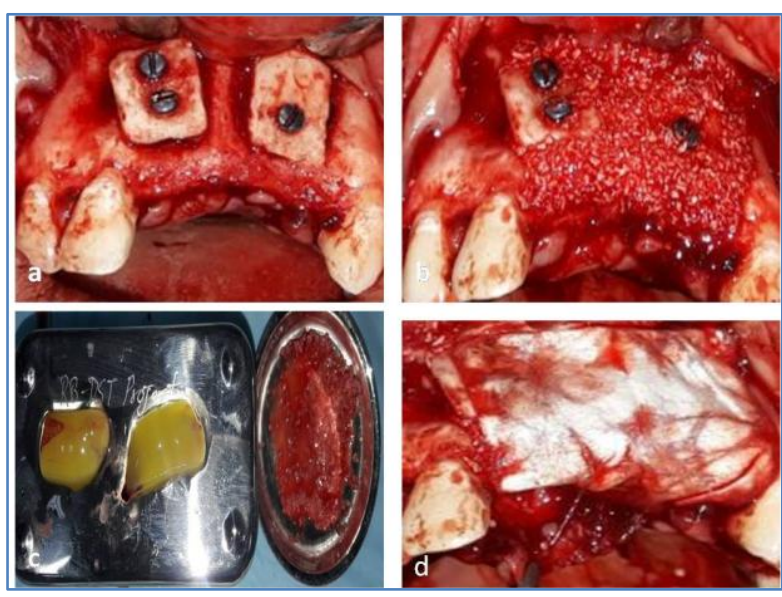

Fig-3
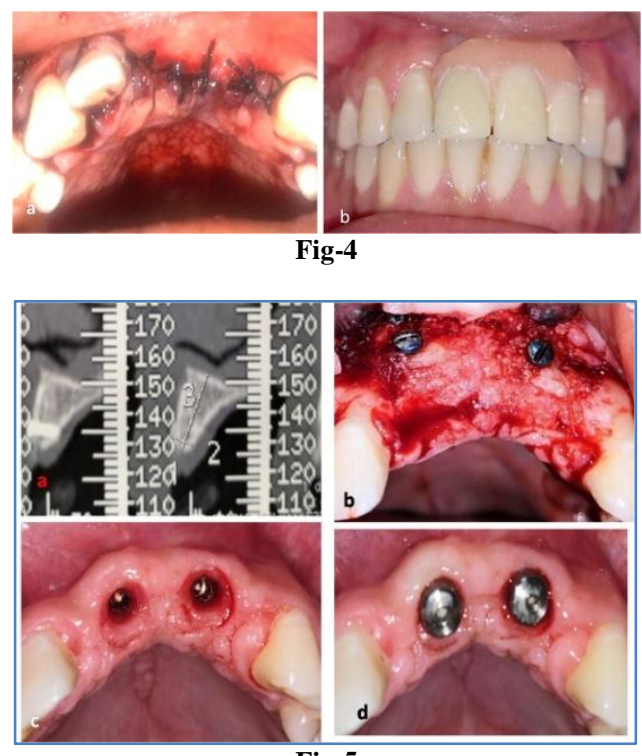

Fig-5 
Vandita Srivastva et al; Saudi J Oral Dent Res, March 2020; 5(3): 203-205

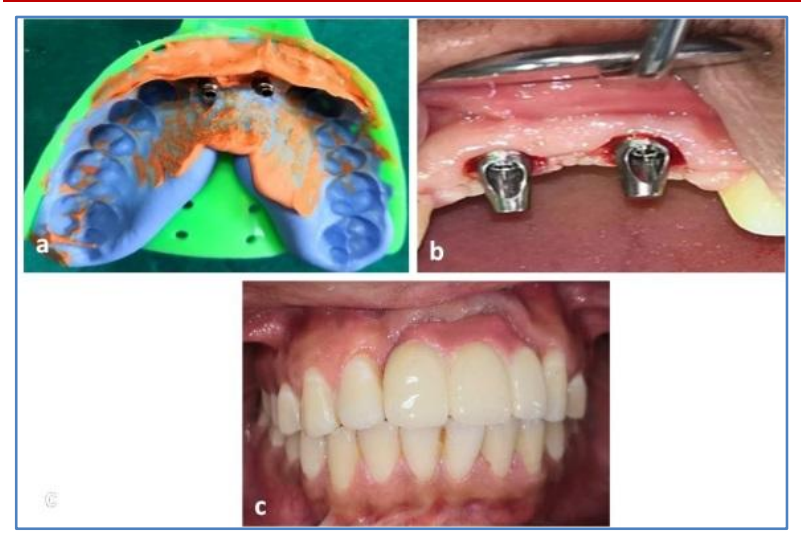

Fig-6

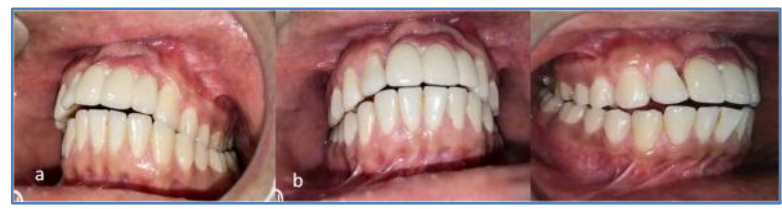

Fig-7

\section{DISCUSSION}

Autogenous graft is considered as the gold standard in grafting procedures. With autogenous grafting immunological reactions are absent. The use of autogenous block graft for augmentation in maxillary anterior region is a predictable option [6]. After augmentation implants can be placed in prosthetically driven manner. Autogenous grafts can be taken extraorally and intraorally. Extraoral sites are tibia, calvarium, iliac crest, rib. Harvesting grafts from extraoral sites need hospitalisation and general anesthesia which increases cost. Harvesting graft from intraoral sites is preferred for implant placement. Intraoral sites include ramus, symphysis, retromolar pad and maxillary tuberosity. Most common source of intraoral graft is ramus and symphysis. Surgical asses may be difficult and may cause damage to inferior alveolar nerve injury while harvesting graft from ramus region [4]. In this case graft is taken from mandibular symphysis region. Corticocancellous bone grafts can be taken from symphysis. Care should be taken to avoid injury to root tips and mental foramen. After augmentation bone width is adequate so implants can be placed in better manner.

\section{CONCLUSION}

Using intraoral block graft is a predictable option for ridge augmentation. Implants can be placed successfully in maxillary atrophic anterior region after augmentation. Implant placement in augmented bone presents higher survival rate.

\section{REFERENCES}

1. Walid, Al-Jallad. (2014). Restoration of Missing Upper Anterior Teeth using Dental imlant Simultaneous with Bone Grafting- A Case Report. J Dent Oral Health, 1: 1-8

2. Bashutski, J.D., Wang, H.L.(2007). Common implant esthetic complications. Implant Dent, 16(4):340-8.

3. Thoma, D. S., Maggetti, I., Waller, T., Hammerle, C. H. F., \& Jung, R. E. (2019). Clinical and patientreported outcomes of implants placed in autogenous bone grafts and implants placed in native bone: a case-control study with a follow up of 5 to 16 years. Clinical Oral Implants Research.

4. Montazem, A., Valauri, D.V., St-Hilaire, H., Buchbinder, D.(2000). Th e mandibular symphysis as a donor site in maxillofacial bone graft s: A quantitative anatomic study. J Oral Maxillofac Surg, 58:1368-71.

5. Sakkas, A., Wilde, F., Heufelder, M., Winter, K., Schramm, A.(2017). Autogenous bone grafts in oral implantology-is it still a "gold standard"? A consecutive review of 279 patients with 456 clinical procedures. Int J Implant Dent, 3(1):23.

6. Schwartz-Arad, D., Levin, L.(2005). Intraoral autogenous block onlay bone grafting for extensive reconstruction of atrophic maxillary alveolar ridges. J Periodontol, 76(4):636-41.

7. Linkow, L.I.(1983). Bone transplants using the symphysis, the iliac crest and synthetic bone materials. J Oral Implantol, 11:211-247. 